\title{
SDF-1/CXCR4 axis modulates bone marrow mesenchymal stem cell apoptosis, migration and cytokine secretion
}

\author{
Xiaolei Liu ${ }^{1 *}$, Biyan Duan ${ }^{2 *}$, Zhaokang Cheng ${ }^{1}, \mathrm{Xiaohua} \mathrm{Jia}^{1}$, Lina Mao ${ }^{1,4}$, Hao Fu${ }^{1}$, Yongzhe Che ${ }^{3}$, \\ Lailiang $\mathrm{Ou}^{1}{ }^{1 凶}$, Lin Liu ${ }^{1}$, Deling Kong ${ }^{1}$ \\ 1 The Key Laboratory of Bioactive Materials, Ministry of Education, College of Life Science, Nankai University, Tianjin 300071, \\ China \\ 2 College of Pharmacy, Nankai University, Tianjin 300071, China \\ 3 School of Medicine, Nankai University, Tianjin 300071, China \\ ${ }^{4}$ Current address: Oklahoma Medical Research Foundation, Oklahoma City, OK 73104, USA \\ $\bowtie$ Correspondence: ouyll@nankai.edu.cn (L.Ou), kongdeling@nankai.edu.cn (D. Kong) \\ Received July 21, 2011 Accepted August 31, 2011
}

\begin{abstract}
Bone marrow mesenchymal stem cells (MSCs) are considered as a promising cell source to treat the acute myocardial infarction. However, over $90 \%$ of the stem cells usually die in the first three days of transplantation. Survival potential, migration ability and paracrine capacity have been considered as the most important three factors for cell transplantation in the ischemic cardiac treatment. We hypothesized that stromal-derived factor-1 (SDF-1)/CXCR4 axis plays a critical role in the regulation of these processes. In this study, apoptosis was induced by exposure of MSCs to $\mathrm{H}_{2} \mathrm{O}_{2}$ for $2 \mathrm{~h}$. After re-oxygenation, the SDF-1 pretreated MSCs demonstrated a significant increase in survival and proliferation. SDF-1 pretreatment also enhanced the migration and increased the secretion of pro-survival and angiogenic cytokines including basic fibroblast growth factor and vascular endothelial growth factor. Western blot and RT-PCR demonstrated that SDF-1 pretreatment significantly activated the pro-survival Akt and Erk signaling pathways and up-regulated $\mathrm{Bcl}-2 / \mathrm{Bax}$ ratio. These protective effects were partially inhibited by AMD3100, an antagonist of CXCR4. We conclude that the SDF-1/CXCR4 axis is critical for MSC survival, migration and cytokine secretion.
\end{abstract}

KEYWORDS SDF-1/CXCR4, bone marrow mesenchy- mal stem cells, survival, migration, secretion

\section{INTRODUCTION}

Bone marrow mesenchymal stem cells (MSCs) are a population of non-hematopoietic and fibroblast-like cells, representing $0.001 \%-0.01 \%$ of the nucleated cells in the marrow (Pittenger et al., 1999). MSCs are considered as a cellular substrate for the cardiac repair because of their presumptive plasticity, genetic stability, and immune tolerance (Trivedi et al., 2010). Furthermore, the accessibility, ease of handling, and enormous expansion potential of MSCs, together with their capacity for self-renewal and amenability to allogenic transplantation (Amado et al., 2005; Dai et al., 2005), provide a nearly unlimited supply of cells for therapeutic applications. The effect of MSCs is thought to be mediated by secreting a number of cardio-protective cytokines and growth factors in addition to differentiation (Kinnaird et al., 2004a, 2004b; Nagaya et al., 2005). Despite initial optimism, MSC transplant therapy has been stymied by the low cellular survival rate after transplantation in the first few days (Toma et al., 2002). The infarcted region usually consists of ischemic and scar tissue which cannot transport enough nutrient and oxygen to support the engraftment and survival of the transplanted stem cells. Most transplanted cells die in the first few hours due to ischemia, inflammation and apoptosis (Menasché, 2008). Thus, it is necessary to reinforce MSC survival against the arduous hypoxic and

"These authors contributed equally to the work. 
hypotrophic microenvironment.

Considering that cell survival is essential for the success of stem cell therapy, many approaches have been utilized to enhance the survival rate of the transplanted cells. Overexpression of pro-survival molecules including Akt (Mangi et al., 2003), Pim-1 (Fischer et al., 2009), Bcl-2 (Li et al., 2007) and stem cell factor (SCF) (Fazel et al., 2008) prevented donor cells from apoptosis. At the same time, pharmacological preconditioning with growth factors and cytokines can also improve the survival of transplanted cells (Haider and Ashraf, 2008).

The stromal-derived factor-1 (SDF-1) plays an essential role in stem cell homing toward the ischemic/hypoxic myocardium by recruiting the progenitor cells that express its cognate receptor, CXC chemokine receptor 4 (CXCR4) (Askari et al., 2003; Abbott et al., 2004). Our previous study showed that overexpression of CXCR4 increased engraftment of MSCs in the infarcted myocardium and improved cardiac performance (Cheng et al., 2008c). We also demonstrated that granulocyte colony-stimulating factor (G-CSF) mobilized MSCs to the infarcted heart through the upregulation of CXCR4 (Cheng et al., 2008a). Beside the role in migration, the SDF-1/CXCR4 axis is also important for cell survival. It has been shown that SDF-1 promoted survival of CD $34^{+}$cells through increasing the expression of the antiapoptotic protein bcl-2 (Lataillade et al., 2002). SDF-1 also protected cardiac myocytes against ischemia/reperfusioninduced cell death (Hu et al., 2007). However, the effects and underlying mechanisms of SDF-1 treatment on survival and secretion function of MSCs are largely unknown. In this study, we demonstrated the positive effects of SDF-1 pretreatment on MSC survival, migration, and cytokine production after hypoxia/de-oxygenation.

\section{RESULTS}

\section{SDF-1 promotes survival and proliferation of MSCs through the SDF-1/CXCR4 axis}

MTT cell proliferation assay was performed to examine whether SDF-1 pretreatment promoted survival and proliferation of MSCs after re-oxygenation. As shown in Fig. 1A, after $16 \mathrm{~h}$ of re-oxygenation, the cell number showed a markedly decrease compared to that after only $2 \mathrm{~h}$, indicating an increasingly cell injury with $\mathrm{H}_{2} \mathrm{O}_{2}$ exposure. Interestingly, SDF-1 treatment $(\mathrm{H}+$ SDF) significantly increased the number of MSCs compared with non-treated group $(\mathrm{H})$. The effect of SDF-1 was impaired by pre-treatment with the CXCR4 antagonist AMD3100 $(\mathrm{H}+$ $A M D+S D F-1)$, indicating SDF-1 promoted MSC proliferation through the SDF-1/CXCR4 ligation.

We also analyzed cell survival by measuring lactate dehydrogenase $(\mathrm{LDH})$ released into the culture medium. As shown in Fig. 1B, LDH release was decreased by SDF-1 $(H+$ $\mathrm{SDF}$ ) compared to non-treated cells $(\mathrm{H})$. Pre-treatment with
A

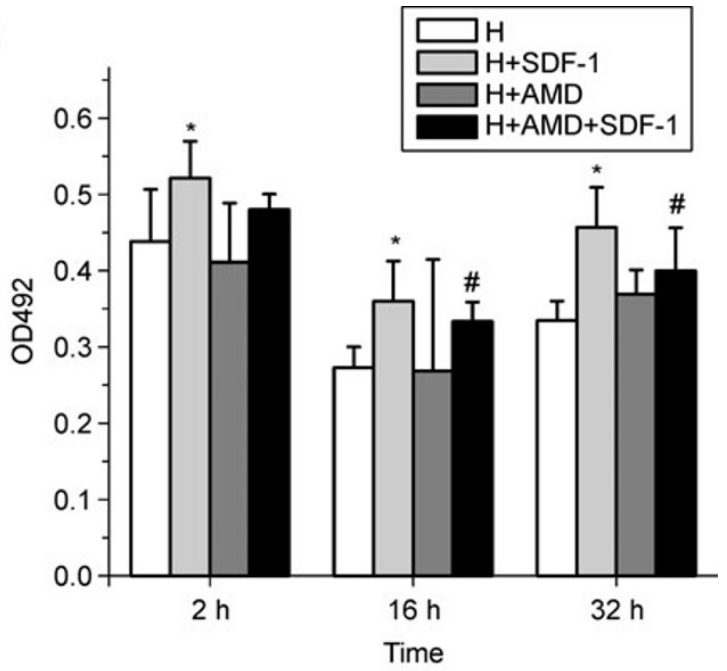

B

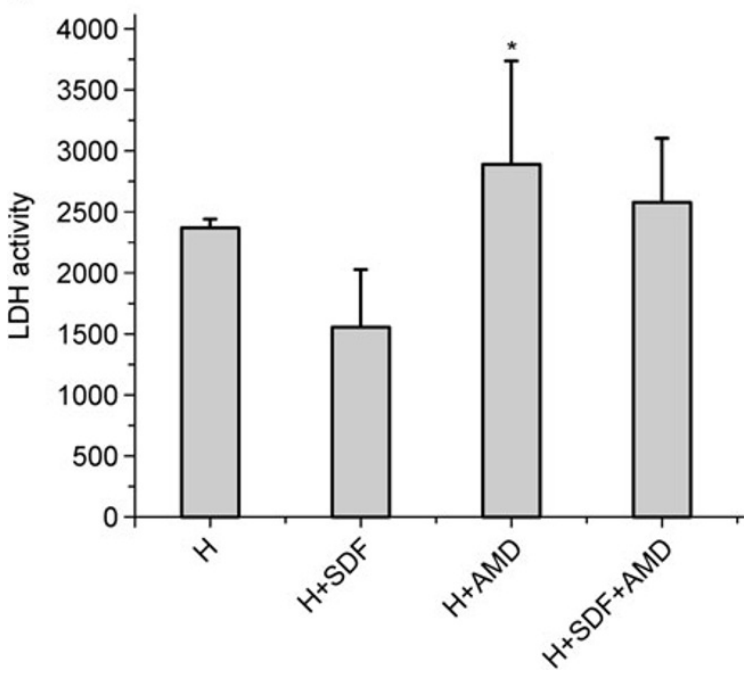

Figure 1. SDF-1 promotes survival and proliferation of MSCs through the SDF-1/CXCR4 axis. (A) MSC proliferation measured by MTT assay. *: $p<0.05$ vs hypoxia $(\mathrm{H})$; \#: $p<0.05$ vs hypoxia, $n=3$. (B) MSC apoptosis measured by LDH release assay. ${ }^{*}: p<0.05$ vs pretreated with SDF-1, $n=3 . \mathrm{H}$, hypoxia, MSCs exposed to $\mathrm{H}_{2} \mathrm{O}_{2}$ for $2 \mathrm{~h}$; SDF, pretreatment with SDF-1 for $1 \mathrm{~h}$; AMD, pretreatment with AMD3100 for $2 \mathrm{~h}$.

AMD3100 $(H+$ AMD + SDF-1) blocked the protective effect of SDF-1, suggesting SDF-1 promoted survival of MSCs through the SDF-1/CXCR4 axis.

\section{SDF-1 activates the Akt and Erk pathways through the SDF-1/CXCR4 axis}

The Akt and Erk signaling pathways are critical for survival and proliferation of MSCs (Mangi et al., 2003; Xu et al., 2008). Thus we postulated that SDF-1 might regulate MSC survival and proliferation through the Akt and Erk pathways. Western blotting showed that SDF-1 induced phosphorylation of both 
Akt and Erk, which were also abolished by pretreatment with AMD3100 (Fig. 2).

\section{SDF-1 increases $\mathrm{Bcl}-2 / \mathrm{Bax}$ ratio through the SDF-1/CXCR4 axis}

The Bcl-2 family proteins, including the pro-survival $\mathrm{Bcl}-2$ and pro-apoptotic Bax, are key regulators of apoptosis (Misao et al., 1996; Li et al., 2007). To determine whether SDF-1 pretreatment modify the expression of Bcl-2 and Bax, MSCs were pretreated with SDF-1 for $1 \mathrm{~h}$ and then exposed to $\mathrm{H}_{2} \mathrm{O}_{2}$ followed by re-oxygenation for $16 \mathrm{~h}$. Western blotting showed that $\mathrm{Bcl}-2$ level was increased in SDF-1 pretreated cells, but was significantly lower in AMD3100-treated cells (Fig. 3A). Although protein level of Bax was not significantly different among the four groups, SDF-1 treatment significantly increased the $\mathrm{Bcl}-2 / \mathrm{Bax}$ ratio to 1.7 fold compared to the control group. In contrast, pretreatment with AMD3100 completely abolished the effects of SDF-1. At mRNA level (Fig. 3B), SDF-1 treatment also significantly increased $\mathrm{Bcl}-2 / \mathrm{Bax}$ ratio, which was blocked by AMD3100. These results suggested that SDF-1 pretreatment increased $\mathrm{Bcl}-2 / \mathrm{Bax}$ ratio through the SDF-1/CXCR4 axis.

A
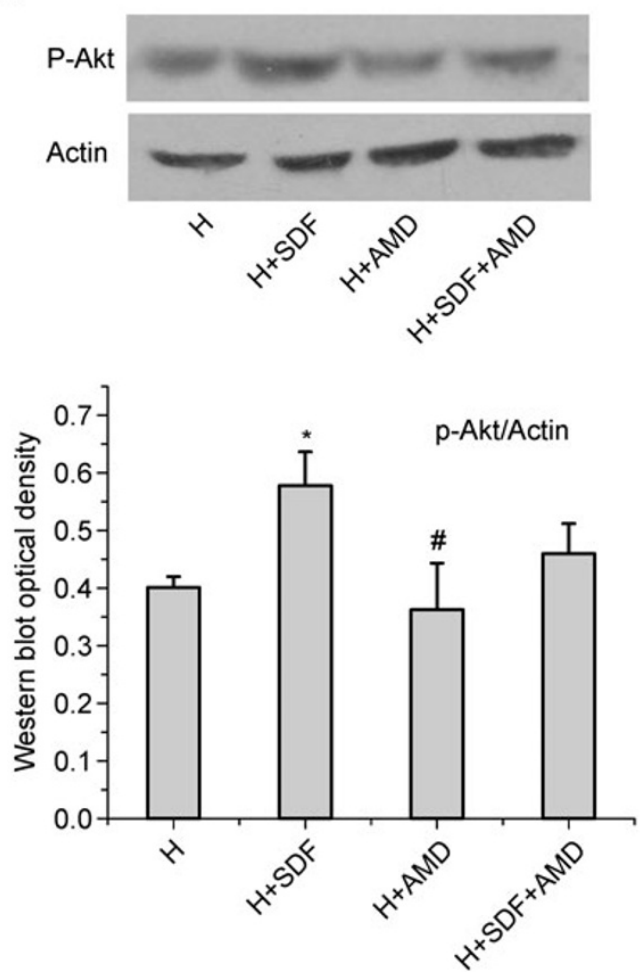

\section{SDF-1 enhances MSC migration}

We examined whether SDF-1 pretreatment could influence the chemotaxis of MSCs toward the SDF-1 gradient in a transwell migration assay. As shown in Fig. 4, SDF-1 pretreatment resulted in a 2-fold increase in the number of migrating MSCs $(p<0.05)$, thereby indicating that SDF-1 pretreatment enhanced the response of MSCs to the SDF-1induced chemotaxis.

\section{Effects of SDF-1 pretreatment on MSC surface CXCR4 expression}

Our previous results showed that increased surface CXCR4 expression was associated with enhanced MSC migration (Cheng et al., 2008a, 2008c). To determine whether SDF-1 enhanced MSC migration through modulation of cell surface CXCR4 expression, MSCs were incubated with SDF-1 before hypoxia/re-oxygenation for $16 \mathrm{~h}$. Flow cytometry analysis showed that SDF-1 tended to increase surface CXCR4 expression compared to non-treated cells, but this did not reach statistical significance (Fig. $5 ; 2.0 \%$ vs $1.4 \%$, $p>0.05)$.

B
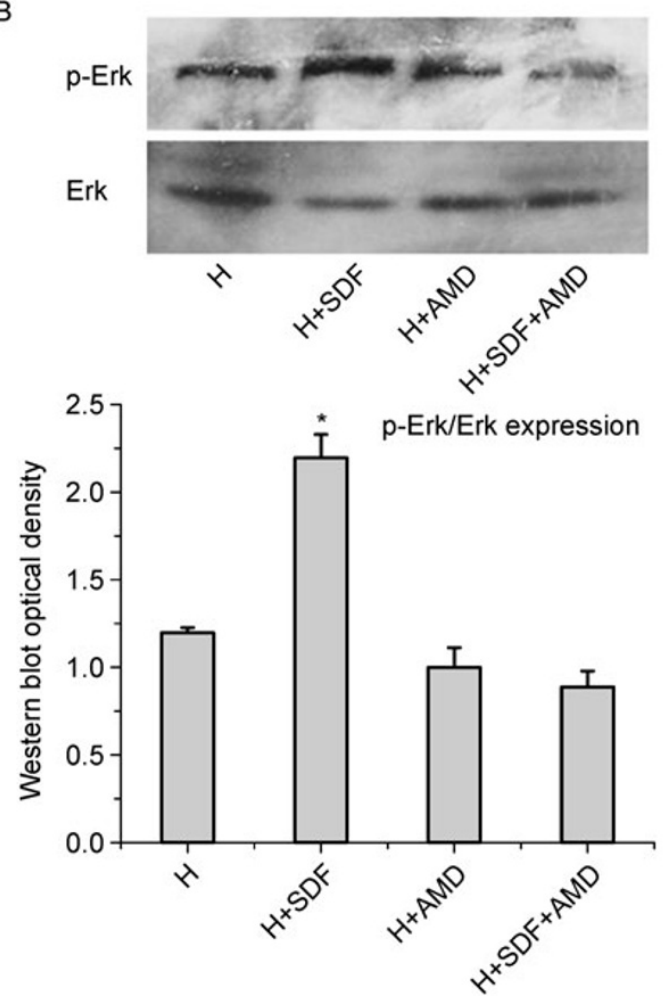

Figure 2. SDF-1 activates the Akt and Erk survival pathways through the SDF-1/CXCR4 axis. (A) SDF-1 pretreatment increased Akt phosphorylation, which could be blocked by AMD3100. (B) SDF-1 pretreatment increased ERK phosphorylation, which could also be blocked by AMD3100.*: $p<0.05$ vs hypoxia; \#: $p<0.05$ vs SDF-1. Data are representative of three independent experiments. 
A
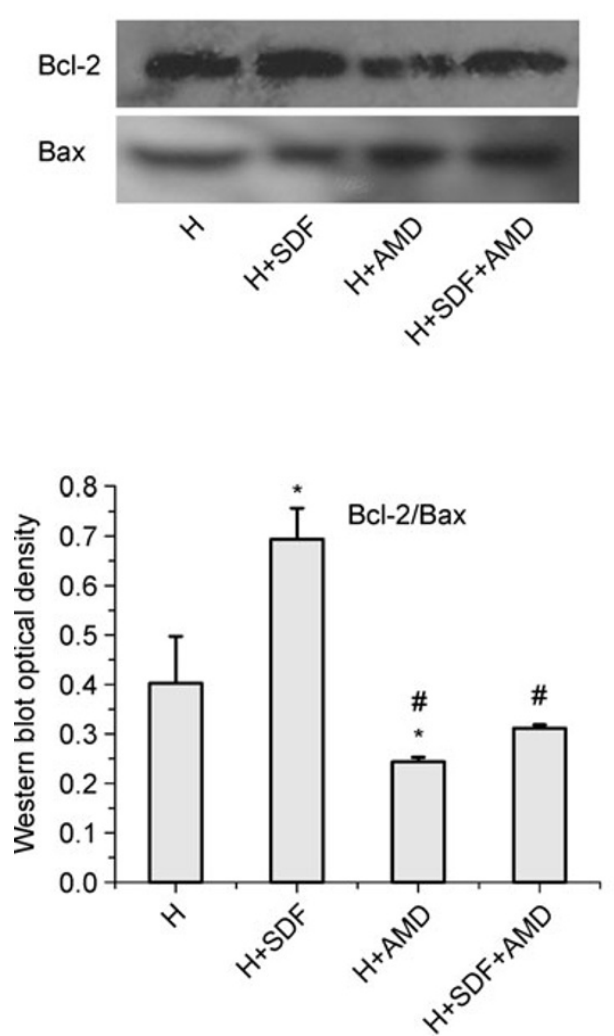

B
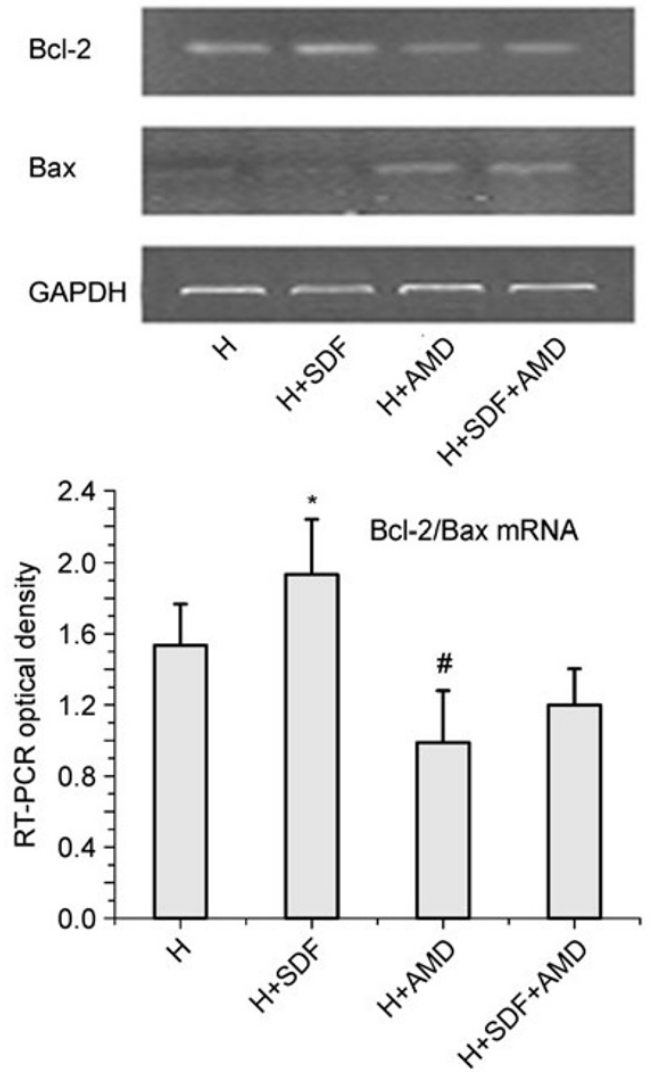

Figure 3. SDF-1 increases Bcl-2/Bax ratio through the SDF-1/CXCR4 axis. (A) Western blot densitometry analysis of Bcl-2 and Bax expression. Representative western blot of $\mathrm{Bcl}-2$, bax and relative $\mathrm{Bcl}-2 / \mathrm{bax}$ ratio are shown. (B) Bcl-2 and Bax mRNA were analyzed by RT-PCR. RT-PCR densitometry showed a significant decrease in bcl-2/bax mRNA ratio when cells were blocked with AMD3100. *: $p<0.05$ vs hypoxia; \#: $p<0.05$ vs SDF-1. Data are representative of three independent experiments.

\section{SDF-1 promotes the secretion of bFGF and VEGF through the SDF-1/CXCR4 axis}

Paracrine secretion of basic fibroblast growth factors (bFGF) and vascular endothelial growth factor (VEGF) is crucial for protecting MSCs in ischemic tissues (Kinnaird et al., 2004a). Therefore we examined the effects of SDF-1 pretreatment on the secretion capacity of MSCs by ELISA. As shown in Fig. $6 \mathrm{~A}, \mathrm{bFGF}$ secretion was significantly enhanced by SDF-1, but the enhancement was almost completely blocked by adding AMD3100 together. Compared to the non-treated cells, SDF1 only slightly increased VEGF secretion by MSCs (Fig. 6B). However, AMD3100 pretreatment significantly inhibited the VEGF production, indicating MSC secretion of VEGF is regulated, at least in part, by the SDF-1/CXCR4 axis.

\section{SDF-1 pretreatment upregulates SDF-1 mRNA in MSCs}

We further examined the effect of SDF-1 treatment on the endogenous SDF-1 expression in MSCs. After re-oxygenation for $16 \mathrm{~h}, \mathrm{SDF}-1$-treated MSCs showed an increase of
SDF-1 mRNA, which was completely blocked by incubation with AMD3100 (Fig. 7). Our data suggested that SDF-1 pretreatment further increased SDF-1 synthesis through the SDF-1/CXCR4 axis, indicating a possible autocrine positive feedback loop.

\section{DISCUSSION}

Stem cell therapy has recently been proposed as a promising strategy for cardiac repair after myocardial infarction (Mangi et al., 2003; Amado et al., 2005; Dai et al., 2005; Li et al., 2007; Xie et al., 2007; Cheng et al., 2008c; Fazel et al., 2008; Fischer et al., 2009). However, most ransplanted stem cells undergo apoptosis in the harsh microenvironment with poor blood and oxygen supply in the infarct zone (Haider and Ashraf, 2008). Therefore, protection of stem cells from apoptosis is crucial for a successful cell therapy. After myocardial infarction and reperfusion, reactive oxygen species (ROS) are generated in the ischemic myocardium and directly cause apoptosis. The in vivo oxidative stressinduced apoptosis can be simulated in vitro by $\mathrm{H}_{2} \mathrm{O}_{2}$ 
A

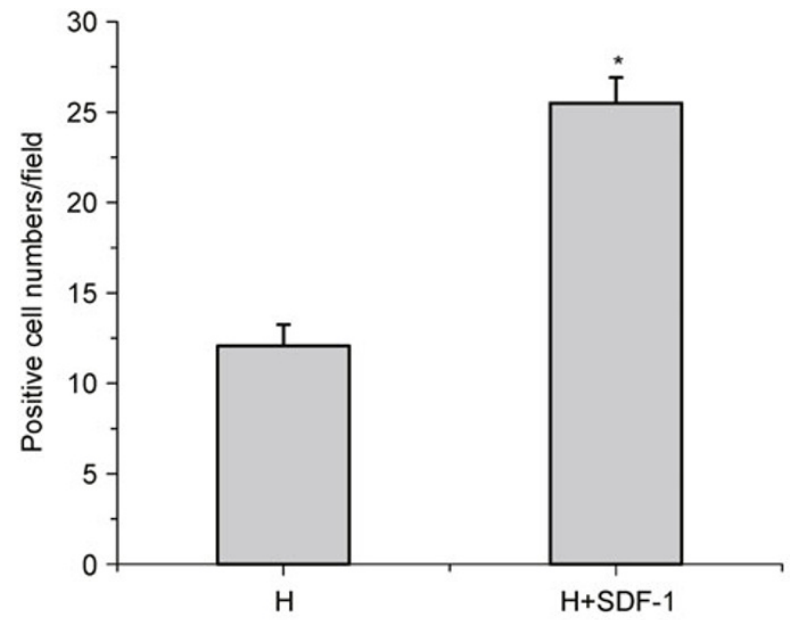

B
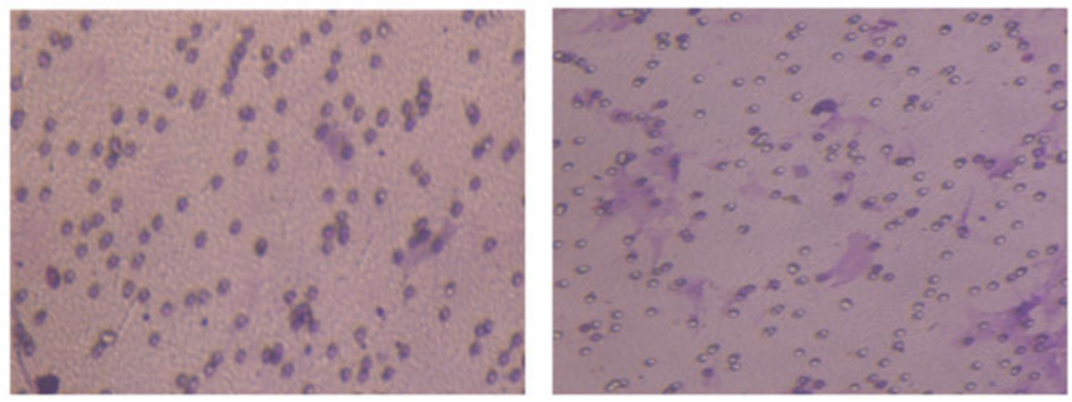

Figure 4. SDF-1 enhances MSC migration. (A) Quantitative analysis of migrated cells in transwell assay. (B) Representative image of hypoxic MSCs (left) and MSCs pretreated with SDF-1 prior to hypoxia (right) in response to $30 \mathrm{ng} / \mathrm{mL} \mathrm{SDF-1}$ in the transwell assay. Results are mean values \pm SEM of five different fields from four independent experiments. *: $p<0.05$ vs hypoxia.

treatment of both isolated adult cardiomyocytes and MSCs (Kumar and Jugdutt, 2003; Pasha et al., 2008). In the present study, we have shown that SDF-1 pretreatment can protect MSCs from $\mathrm{H}_{2} \mathrm{O}_{2}$-induced damages. SDF-1 pretreatment significantly attenuates oxidative stress-induced MSC apoptosis; furthermore, SDF-1 markedly activates the Akt and Erk survival pathways and increases the $\mathrm{Bcl}-2 / \mathrm{Bax}$ ratio; besides, SDF-1 pretreatment improves migration capability of MSCs; and finally, SDF-1 enhances the secretion of bFGF and VEGF by MSCs. These findings clearly demonstrate that pretreatment of MSCs by SDF-1 can improve the efficacy of stem cell therapy.

SDF-1 is a CXC chemokine known to be an effective chemotactic factor for progenitor cells and mature blood cells. CXCR4, the cell surface receptor for SDF-1, mediates the homing and migration of stem cells (Cheng et al., 2008c). Previous studies demonstrated that under chronically hypoxic conditions (Rochefort et al., 2006), MSCs were mobilized into the peripheral blood through upregulation of CXCR4 (Schioppa et al., 2003), suggesting that hypoxia potently regulated $\mathrm{CXCR} 4$ expression in vivo. At the same time, the level of SDF-1 was also elevated after myocardial infarction (Askari et al., 2003; Abbott et al., 2004). In our study, we showed that SDF-1 pretreatment improved MSC migration through upregulation of cell surface CXCR4 (Fig. 5). The upregulation of endogenous SDF-1 by SDF-1 pretreatment (Fig. 7), a possible autocrine positive feedback effect, might also play a role in promoting MSC migration.

In addition to its role in cell migration, the SDF-1/CXCR4 axis is also associated with enhanced cell survival/proliferation, adhesion, and growth factor secretion (Kucia et al., 2004). SDF-1 has been shown to promote the survival of myeloid, neural, oligodendrocyte and trophoblast precursors (Broxmeyer et al., 2003; Jaleel et al., 2004; Dziembowska et al., 2005). It was reported that overexpression of SDF-1 improved survival of MSCs in the ischemic heart (Zhang et al., 2007). In the present study, we also demonstrated that SDF-1 pretreatment improved MSC survival and proliferation. Pretreatment with the CXCR4 antagonist AMD3100 significantly decreased cell viability (Fig. 1B). These results suggested that the anti-apoptotic effect of SDF-1 was mediated through its cognate receptor, CXCR4.

Although SDF-1 pretreatment improved cell survival and differentiation (Joo et al., 2004; Pasha et al., 2008), the mechanism has not been well elucidated. Previous studies suggested that cell survival and proliferation are mediated 
A

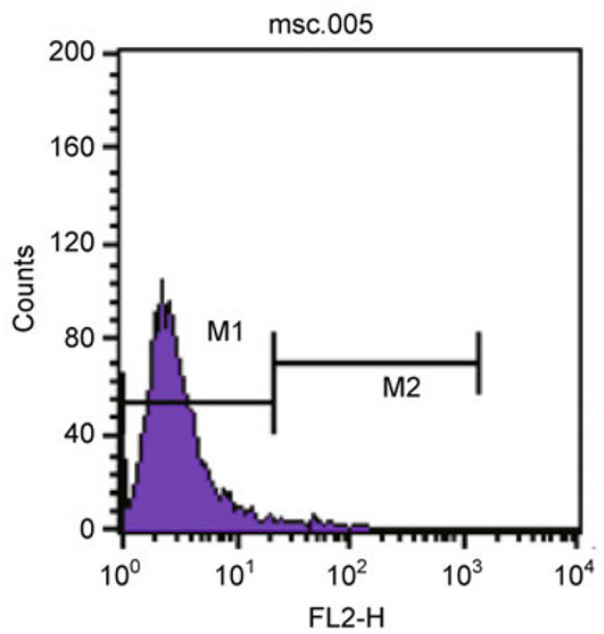

File: msc.005

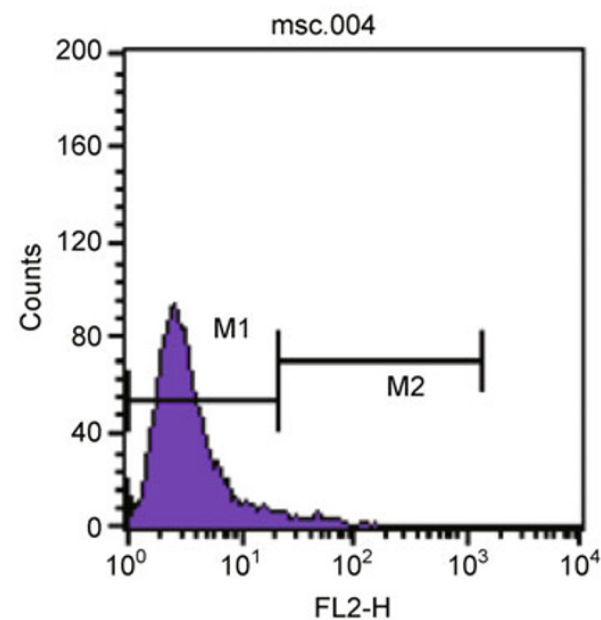

File: msc.004 Acquisition Date:07-Jan-09

\begin{tabular}{rrrrr} 
Marker & Left, Right & Events & \% Gated & $\%$ Total \\
\hline All & 1,9910 & 9016 & 100.00 & 90.16 \\
M1 & $1, \quad 21$ & 8854 & 98.20 & 88.54 \\
M2 & 21,1382 & 167 & 1.85 & 1.67
\end{tabular}

B

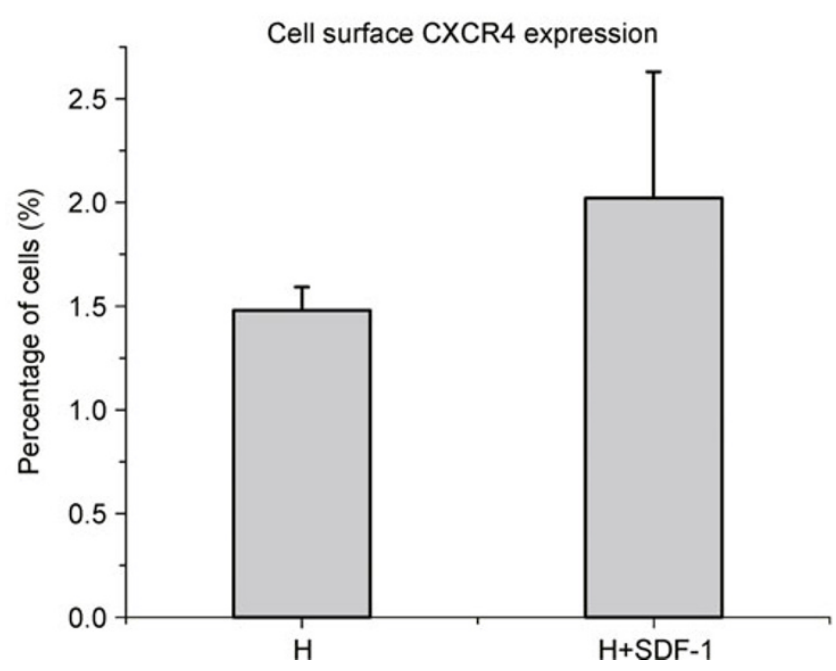

Figure 5. Effect of SDF-1 pretreatment on MSC surface CXCR4 expression. (A) Representative flow cytometry images of surface CXCR4 expression on MSCs pretreated with $0 \mathrm{ng} / \mathrm{mL}$ SDF-1 (left) or $50 \mathrm{ng} / \mathrm{mL}$ SDF-1 (right) before hypoxia/re-oxygenation for $16 \mathrm{~h}$. (B) Quantitative analysis of surface CXCR4 expression on MSCs. Results are mean \pm SEM ( $n=5$ in each group). The difference was not significant according to the independent $t$-test.

through activation of the signaling cascades PI3K/Akt and MAPK/ERK (Choi et al., 2008; Zhang and Cai, 2010). Our data showed that SDF-1 mediated MSC survival was associated with increased phosphorylation of Akt and ERK, which can be blocked by AMD3100 (Fig. 2). Our results suggested that SDF-1, acting through its receptor CXCR4, protected MSCs from apoptosis via activation of Akt and ERK.

We also investigated the expression of $\mathrm{Bcl}-2$ family proteins. Bcl-2 is an anti-apoptotic protein which serves as a critical regulator of pathways involved in apoptosis (Reed, 1998), whereas Bax is a pro-apoptotic protein which controls the integrity of the mitochondrial outer membrane (Yang et al., 1997; Jürgensmeier et al., 1998). Here we found pretreatment with SDF-1 increased the expression of $\mathrm{Bcl}-2$ while decreased Bax level. In agreement with our results, SDF-1 has been shown to prevent the apoptosis of hematopoietic precursors through the upregulation of Bcl-2 (Peters et al., 1998). 
A

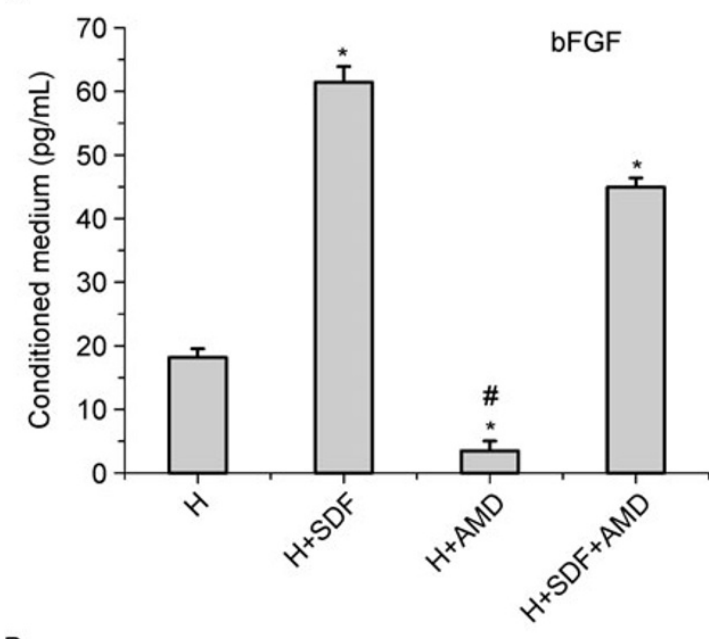

B

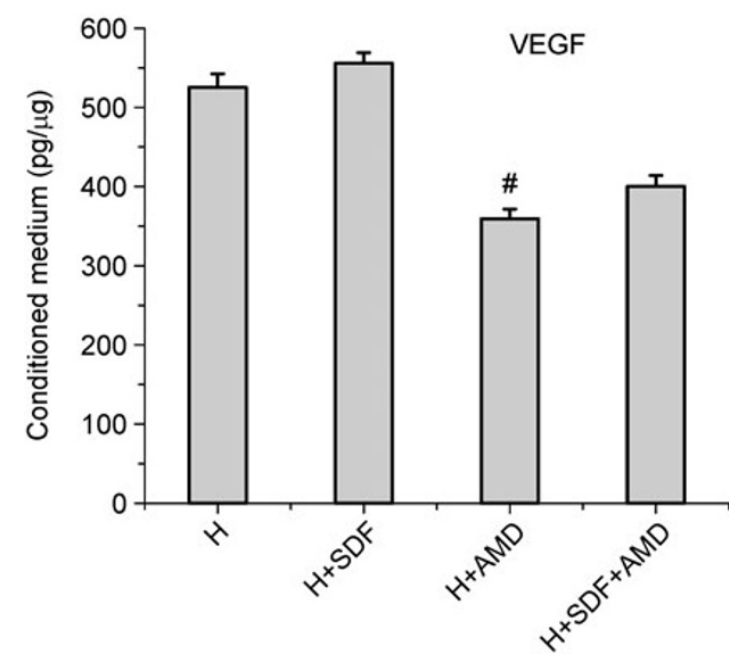

Figure 6. SDF-1 stimulates MSCs to secrete cytokines through the SDF-1/CXCR4 axis. (A) SDF-1 pretreatment increased bFGF secretion, which could be blocked by AMD3100. (B) Secretion of VEGF by MSCs was blocked by AMD3100. *: $p<0.05$ vs hypoxia; \#: $p<0.05$ vs SDF-1. Data are representative of three independent experiments.

MSCs can secrete angiogenic cytokines including bFGF and VEGF (Kinnaird et al., 2004a), both of which have been shown to inhibit cellular apoptosis (Gupta et al., 1999; Choi et al., 2008). Our study revealed that SDF-1 pretreatment increased the secretion of bFGF and VEGF by MSCs, whereas blocking of CXCR4 by AMD3100 abolished this effect (Fig. 6). These results suggest that SDF-1 pretreatment can protect the resident cardiomyocytes from apoptosis and improve their survival by paracrine secretion of bFGF and VEGF.

In conclusion, our results showed that SDF-1 pretreatment increases the survival, proliferation, migration and secretion capability of MSCs. These effects of SDF-1 are mediated through its receptor CXCR4.

\section{MATERIALS AND METHODS}

\author{
Isolation and culture of MSCs
}

Male Sprague-Dawley (SD) rats were purchased from the Lab Animal Center of The Academy of Military Medical Sciences (Beijing, China). Bone marrow MSCs were isolated as described previously (Cheng et al., 2008c). Briefly, adult male SD rats were euthanatized, and bone marrow from tibias and femurs was flushed with complete culture medium. Mononuclear cells were separated by density-gradient centrifugation with Ficoll-Paque ${ }^{\mathrm{TM}}$ PLUS (Amersham Biosciences, Uppsala, Sweden). Cells were resuspended in aMEM (Gibco Laboratories, Grand Island, NY, USA) supplemented with $20 \%$ fetal bovine serum and antibiotics. Non-adherent cells (hematopoietic cells, fibroblasts, etc.) were washed away during medium changes, while MSCs retained because of their preferential attachment to the polystyrene surfaces. The study protocol was approved by the Ethics Committee on Animal Experimentation of Nankai University (A552101), which complies with the Guide for the Care and Use of Laboratory Animals published by the US National Institutes of Health (NIH Publication No. 85-23, revised 1996).

\section{SDF-1 pretreatment and hypoxia/re-oxygenation}

MSCs were stimulated with SDF-1 $(50 \mathrm{ng} / \mathrm{mL})$ for $1 \mathrm{~h}$ before exposure to $\mathrm{H}_{2} \mathrm{O}_{2}(200 \mu \mathrm{mol} / \mathrm{L})$ for $2 \mathrm{~h}$. In control group, cells were cultured with CXCR4-specific antagonist AMD3100 $(10 \mu \mathrm{g} / \mathrm{mL})$ for $2 \mathrm{~h}$. Cells were then cultured in normal growth medium for 2,16 or $32 \mathrm{~h}$. The supernatant from $16 \mathrm{~h}$ culture was collected for ELISA analysis.

\section{MTT cell proliferation assay}

Cell proliferation was assessed by MTT method. Briefly, MSCs were seeded in 96 wells at $1 \times 10^{5}$ cells/well in $100 \mu \mathrm{L}$ complete medium. After hypoxia/re-oxygenation, MSCs were cultured for 2,16 or $32 \mathrm{~h}$, respectively, followed by the addition of $25 \mu \mathrm{L} \mathrm{MTT}(5 \mathrm{mg} / \mathrm{mL} \mathrm{PBS,} \mathrm{pH}$ 7.4 , Sigma) for another $4 \mathrm{~h}$. The supernatant was then discarded and $100 \mu \mathrm{L}$ DMSO was added into each well for $10 \mathrm{~min}$. Finally, absorbance at $492 \mathrm{~nm}$ was measured with a Bio-Rad Microplate Reader.

\section{LDH cytotoxicity assay}

Lactate dehydrogenase (LDH) is a cytoplasmic oxidoreductase that is released into the culture supernatant when the plasma membrane is damaged. The degree of cellular injury thus can be monitored by measuring the amount of LDH released by the cells. In this study, LDH level in the culture medium was assayed by LDH ELISA according to the manufacturer's protocol (Jiancheng Co., Nanjing, China).

\section{Flow cytometry analysis of surface CXCR4 expression}

Surface CXCR4 expression was analyzed as previously described (Cheng et al., 2008a). Briefly, cells were stained with rabbit antiCXCR4 antibody (Thermo Fisher Scientific, Fremont, CA, USA) followed by Alexa Fluor 594 goat anti-rabbit lgG (Molecular Probes, 
A

SDF-1
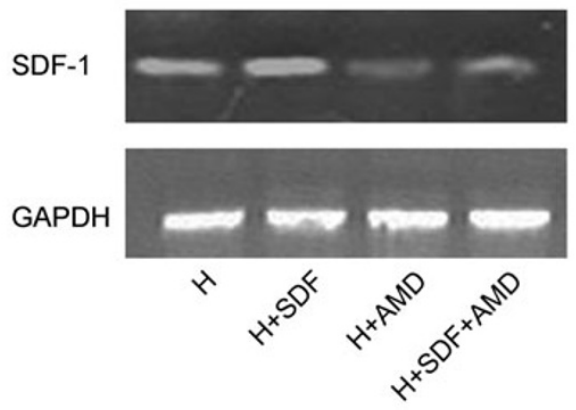

B

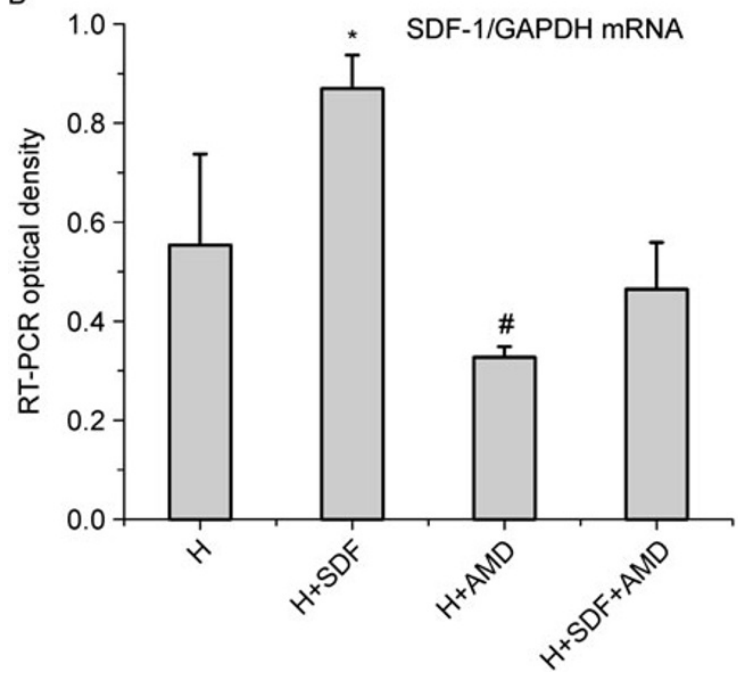

Figure 7. SDF-1 pretreatment upregulates SDF-1 mRNA in MSCs. (A) Representative images of SDF-1 expression detected by RT-PCR. (B) Quantitative analysis of SDF-1 mRNA by densitometry showed a significant decrease in SDF1 expression when cells were blocked with AMD3100 for $2 \mathrm{~h}$. *: $p<0.05$ vs hypoxia; \#: $p<0.05$ vs SDF-1. Data are representative of three independent experiments.

Eugene, OR, USA). Surface CXCR4 expression was determined by an Epics Altra flow cytometer (Beckman Coulter, Fullerton, CA, USA).

\section{Transwell migration assay}

Migration assays were performed as previously described (Cheng et al., 2008c). Briefly, after hypoxia/re-oxygenation, cells were placed in the upper chamber of the transwell assembly (Corning Costar, Cambridge, MA) at a density of $6 \times 10^{5} \mathrm{cells} / \mathrm{mL}$. The lower chamber contains $600 \mu \mathrm{L}$ medium with $30 \mathrm{ng} / \mathrm{mL}$ SDF-1 (PeproTech, Rocky Hill, NJ). After incubation at $37^{\circ} \mathrm{C}$ for $10 \mathrm{~h}$, the membrane was stained with $0.5 \%$ crystal violet and the number of migrating cells was determined by counting five random fields per well under the microscope at 100x. Experiments were performed in sets of four for each group.

\section{Reverse transcriptase-polymerase chain reaction analysis}

RNA was isolated using Trizol reagent following the manufacturer's instructions (Invitrogen), and cDNA was synthesized from $2 \mu \mathrm{g}$ of total RNA using reverse transcriptase. Amplification reactions $(30 \mu \mathrm{L})$ were carried out with $3 \mu \mathrm{L}$ of template cDNA and $2.4 \mu \mathrm{mol} / \mathrm{L}$ primers for each gene. PCR reaction mixtures were denatured at $94^{\circ} \mathrm{C}$ for 2 min and cDNA templates amplified as follows: 35 cycles (22 cycles for GAPDH) of denaturation at $94^{\circ} \mathrm{C}$ for $30 \mathrm{~s}$; annealing temperature and time are different depending on primers: SDF- 1 at $61^{\circ} \mathrm{C}$ for $20 \mathrm{~s}$; $\mathrm{Bcl}-2$ at $60^{\circ} \mathrm{C}$ for $45 \mathrm{~s}$; Bax at $57^{\circ} \mathrm{C}$ for $45 \mathrm{~s}$; GAPDH at $55^{\circ} \mathrm{C}$ for $30 \mathrm{~s}$; and extension at $72^{\circ} \mathrm{C}$ for $30 \mathrm{~s}$, with a final extension time of $5 \mathrm{~min}$ at $72^{\circ} \mathrm{C}$. The PCR products were size-fractionated by $1.2 \%$ agarose gel electrophoresis. The sequences of primers were: SDF-1 (116 bp): 5'ATGCCCCTGCCGATTCTTTG-3' (forward), 5'-TGTTGTTGCTTTTCAGCCTTGC-3' (reverse); Bcl-2 (560 bp): 5'-AGATGAAGACTCCGCGCC-3' (forward), 5'-GTAGTGAGACCCACGTATGGACC-3' (reverse); Bax (94 bp): 5'-TTCATCGAGCCCAGCA-3' (forward), 5'-CTCGCTCAGCTTCTTGGTC-3' (reverse); GAPDH (308 bp): 5'-TCCCTCAAGATTGTCAGCAA-3' (forward), 5'-AGATCCACAACGGATACATT-3' (reverse).

\section{Western blot analysis}

Western blot was performed as previously described (Cheng et al., $2008 \mathrm{~b})$. Briefly, cells were incubated with lysis buffer at $4^{\circ} \mathrm{C}$ for $30 \mathrm{~min}$, and then centrifuged for $30 \mathrm{~min}$ at $12,000 \mathrm{rpm}$ at $4^{\circ} \mathrm{C}$. Denatured proteins $(40 \mu \mathrm{g})$ were separated by SDS-PAGE and transferred onto a PVDF membrane. After blocking with $5 \%$ skim milk in $1 \times$ Tris Buffered Saline Tween-20 (TBST, Tris $1.21 \mathrm{~g}, \mathrm{NaCl} 9.00 \mathrm{~g}$, Tween-20 $1 \mathrm{~mL}, \mathrm{ddH}_{2} \mathrm{O} 1 \mathrm{~L}$ ), the membranes were incubated with rabbit anti-bcl-2, rabbit anti-Bax, rabbit anti-p-Erk, goat anti-Erk, rabbit anti-p-Akt and mouse anti-actin (1100, all antibodies were from Santa Cruz Biotechnology Inc., Santa Cruz, CA). Horseradish peroxidaseconjugated goat anti-rabbit lgG, rabbit anti-goat IgG or goat antimouse IgG (11000, Zymed, San Francisco, CA) was used as the secondary antibody. Hybridizing bands were visualized using SuperSignal West Pico Substrate (Pierce, Rockford, IL). The signals were quantified by densitometry.

\section{ELISA assay}

Conditioned media were collected after re-oxygenation for $16 \mathrm{~h}$, followed by $10 \mathrm{~min}$ centrifugation at $12,000 \mathrm{rpm}, 4^{\circ} \mathrm{C}$. The concentration of VEGF or bFGF was measured with ELISA kits according to the manufacturer's instruction (ADL Company, Shanghai, China).

\section{Statistical analysis}

Data are expressed as mean \pm SEM. Student's $t$-test was used for two-group comparisons and one-way ANOVA was applied for multiple group comparisons. Statistical significance was obtained when $p \leqslant 0.05$.

\section{ACKNOWLEDGEMENTS}

This work was supported by the National key Basic Research Program of China (Grant Nos. 2011CB964903 and 2011CB606202), 
the National Outstanding Youth Foundation (No. 30725030), the National Natural Science Foundation of China (Grant Nos. 30570471 and 30970746) and the National Key Scientific Program of China (No. 952010).

\section{ABBREVIATIONS}

CXCR4, CXC chemokine receptor 4; G-CSF, granulocyte colonystimulating factor; LDH, lactate dehydrogenase; MSCs, mesenchymal stem cells; ROS, reactive oxygen species; SCF, stem cell factor; $\mathrm{SD}$, Sprague-Dawley; SDF-1, stromal-derived factor-1

\section{REFERENCES}

Abbott, J.D., Huang, Y., Liu, D., Hickey, R., Krause, D.S., and Giordano, F.J. (2004). Stromal cell-derived factor-1alpha plays a critical role in stem cell recruitment to the heart after myocardial infarction but is not sufficient to induce homing in the absence of injury. Circulation 110, 3300-3305.

Amado, L.C., Saliaris, A.P., Schuleri, K.H., St John, M., Xie, J.S., Cattaneo, S., Durand, D.J., Fitton, T., Kuang, J.Q., Stewart, G., et al. (2005). Cardiac repair with intramyocardial injection of allogeneic mesenchymal stem cells after myocardial infarction. Proc Natl Acad Sci U S A 102, 11474-11479.

Askari, A.T., Unzek, S., Popovic, Z.B., Goldman, C.K., Forudi, F., Kiedrowski, M., Rovner, A., Ellis, S.G., Thomas, J.D., DiCorleto, P. E., et al. (2003). Effect of stromal-cell-derived factor 1 on stem-cell homing and tissue regeneration in ischaemic cardiomyopathy. Lancet 362, 697-703.

Broxmeyer, H.E., Kohli, L., Kim, C.H., Lee, Y., Mantel, C., Cooper, S., Hangoc, G., Shaheen, M., Li, X., and Clapp, D.W. (2003). Stromal cell-derived factor-1/CXCL12 directly enhances survival/antiapoptosis of myeloid progenitor cells through CXCR4 and G(alpha)i proteins and enhances engraftment of competitive, repopulating stem cells. J Leukoc Biol 73, 630-638.

Cheng, Z., Liu, X., Ou, L., Zhou, X., Liu, Y., Jia, X., Zhang, J., Li, Y., and Kong, D. (2008a). Mobilization of mesenchymal stem cells by granulocyte colony-stimulating factor in rats with acute myocardial infarction. Cardiovasc Drugs Ther 22, 363-371.

Cheng, Z., Ou, L., Liu, Y., Liu, X., Li, F., Sun, B., Che, Y., Kong, D., Yu, Y., and Steinhoff, G. (2008b). Granulocyte colony-stimulating factor exacerbates cardiac fibrosis after myocardial infarction in a rat model of permanent occlusion. Cardiovasc Res 80, 425-434.

Cheng, Z., Ou, L., Zhou, X., Li, F., Jia, X., Zhang, Y., Liu, X., Li, Y., Ward, C.A., Melo, L.G., et al.(2008c). Targeted migration of mesenchymal stem cells modified with CXCR4 gene to infarcted myocardium improves cardiac performance. Mol Ther 16, 571-579.

Choi, S.C., Kim, S.J., Choi, J.H., Park, C.Y., Shim, W.J., and Lim, D.S. (2008). Fibroblast growth factor-2 and -4 promote the proliferation of bone marrow mesenchymal stem cells by the activation of the PI3K-Akt and ERK1/2 signaling pathways. Stem Cells Dev 17, 725-736.

Dai, W., Hale, S.L., Martin, B.J., Kuang, J.Q., Dow, J.S., Wold, L.E., and Kloner, R.A. (2005). Allogeneic mesenchymal stem cell transplantation in postinfarcted rat myocardium: short- and longterm effects. Circulation 112, 214-223.

Dziembowska, M., Tham, T.N., Lau, P., Vitry, S., Lazarini, F., and Dubois-Dalcq, M. (2005). A role for CXCR4 signaling in survival and migration of neural and oligodendrocyte precursors. Glia 50, 258-269.

Fazel, S.S., Angoulvant, D., Butany, J., Weisel, R.D., and Li, R.K. (2008). Mesenchymal stem cells engineered to overexpress stem cell factor improve cardiac function but have malignant potential. $J$ Thorac Cardiovasc Surg 136, 1388-1389.

Fischer, K.M., Cottage, C.T., Wu, W., Din, S., Gude, N.A., Avitabile, D., Quijada, P., Collins, B.L., Fransioli, J., and Sussman, M.A. (2009). Enhancement of myocardial regeneration through genetic engineering of cardiac progenitor cells expressing Pim-1 kinase. Circulation 120, 2077-2087.

Gupta, K., Kshirsagar, S., Li, W., Gui, L., Ramakrishnan, S., Gupta, P., Law, P.Y., and Hebbel, R.P. (1999). VEGF prevents apoptosis of human microvascular endothelial cells via opposing effects on MAPK/ERK and SAPK/JNK signaling. Exp Cell Res 247, 495 504.

Haider, H.Kh., and Ashraf, M. (2008). Strategies to promote donor cell survival: combining preconditioning approach with stem cell transplantation. J Mol Cell Cardiol 45, 554-566.

Hu, X., Dai, S., Wu, W.J., Tan, W., Zhu, X., Mu, J., Guo, Y., Bolli, R., and Rokosh, G. (2007). Stromal cell derived factor-1 alpha confers protection against myocardial ischemia/reperfusion injury: role of the cardiac stromal cell derived factor-1 alpha CXCR4 axis. Circulation 116, 654-663.

Jaleel, M.A., Tsai, A.C., Sarkar, S., Freedman, P.V., and Rubin, L.P. (2004). Stromal cell-derived factor-1 (SDF-1) signalling regulates human placental trophoblast cell survival. Mol Hum Reprod 10, 901-909.

Joo, E.K., Broxmeyer, H.E., Kwon, H.J., Kang, H.B., Kim, J.S., Lim, J. S., Choe, Y.K., Choe, I.S., Myung, P.K., and Lee, Y. (2004). Enhancement of cell survival by stromal cell-derived factor-1/ CXCL12 involves activation of CREB and induction of Mcl-1 and cFos in factor-dependent human cell line MO7e. Stem Cells Dev 13, 563-570.

Jürgensmeier, J.M., Xie, Z., Deveraux, Q., Ellerby, L., Bredesen, D., and Reed, J.C. (1998). Bax directly induces release of cytochrome c from isolated mitochondria. Proc Natl Acad Sci U S A 95, 4997-5002.

Kinnaird, T., Stabile, E., Burnett, M.S., Lee, C.W., Barr, S., Fuchs, S., and Epstein, S.E. (2004a). Marrow-derived stromal cells express genes encoding a broad spectrum of arteriogenic cytokines and promote in vitro and in vivo arteriogenesis through paracrine mechanisms. Circ Res 94, 678-685.

Kinnaird, T., Stabile, E., Burnett, M.S., Shou, M., Lee, C.W., Barr, S., Fuchs, S., and Epstein, S.E. (2004b). Local delivery of marrowderived stromal cells augments collateral perfusion through paracrine mechanisms. Circulation 109, 1543-1549.

Kucia, M., Jankowski, K., Reca, R., Wysoczynski, M., Bandura, L., Allendorf, D.J., Zhang, J., Ratajczak, J., and Ratajczak, M.Z. (2004). CXCR4-SDF-1 signalling, locomotion, chemotaxis and adhesion. J Mol Histol 35, 233-245.

Kumar, D., and Jugdutt, B.I. (2003). Apoptosis and oxidants in the heart. J Lab Clin Med 142, 288-297.

Lataillade, J.J., Clay, D., Bourin, P., Hérodin, F., Dupuy, C., Jasmin, C., and Le Bousse-Kerdilès, M.C. (2002). Stromal cell-derived factor 1 regulates primitive hematopoiesis by suppressing apoptosis and by promoting $G(0) / G(1)$ transition in CD34(+) cells: evidence for an autocrine/paracrine mechanism. Blood 99, $1117-1129$. 
Li, W., Ma, N., Ong, L.L., Nesselmann, C., Klopsch, C., Ladilov, Y., Furlani, D., Piechaczek, C., Moebius, J.M., Lützow, K., et al. (2007). Bcl-2 engineered MSCs inhibited apoptosis and improved heart function. Stem Cells 25, 2118-2127.

Mangi, A.A., Noiseux, N., Kong, D., He, H., Rezvani, M., Ingwall, J.S., and Dzau, V.J. (2003). Mesenchymal stem cells modified with Akt prevent remodeling and restore performance of infarcted hearts. Nat Med 9, 1195-1201.

Menasché, P. (2008). Current status and future prospects for cell transplantation to prevent congestive heart failure. Semin Thorac Cardiovasc Surg 20, 131-137.

Misao, J., Hayakawa, Y., Ohno, M., Kato, S., Fujiwara, T., and Fujiwara, H. (1996). Expression of bcl-2 protein, an inhibitor of apoptosis, and Bax, an accelerator of apoptosis, in ventricular myocytes of human hearts with myocardial infarction. Circulation 94, 1506-1512.

Nagaya, N., Kangawa, K., Itoh, T., Iwase, T., Murakami, S., Miyahara, Y., Fujii, T., Uematsu, M., Ohgushi, H., Yamagishi, M., et al. (2005). Transplantation of mesenchymal stem cells improves cardiac function in a rat model of dilated cardiomyopathy. Circulation 112 , 1128-1135.

Pasha, Z., Wang, Y., Sheikh, R., Zhang, D., Zhao, T., and Ashraf, M. (2008). Preconditioning enhances cell survival and differentiation of stem cells during transplantation in infarcted myocardium. Cardiovasc Res 77, 134-142.

Peters, R., Leyvraz, S., and Perey, L. (1998). Apoptotic regulation in primitive hematopoietic precursors. Blood 92, 2041-2052.

Pittenger, M.F., Mackay, A.M., Beck, S.C., Jaiswal, R.K., Douglas, R., Mosca, J.D., Moorman, M.A., Simonetti, D.W., Craig, S., and Marshak, D.R. (1999). Multilineage potential of adult human mesenchymal stem cells. Science 284, 143-147.

Reed, J.C. (1998). Bcl-2 family proteins. Oncogene 17, 3225-3236.

Rochefort, G.Y., Delorme, B., Lopez, A., Hérault, O., Bonnet, P., Charbord, P., Eder, V., and Domenech, J. (2006). Multipotential mesenchymal stem cells are mobilized into peripheral blood by hypoxia. Stem Cells 24, 2202-2208.

Schioppa, T., Uranchimeg, B., Saccani, A., Biswas, S.K., Doni, A., Rapisarda, A., Bernasconi, S., Saccani, S., Nebuloni, M., Vago, L., et al. (2003). Regulation of the chemokine receptor CXCR4 by hypoxia. J Exp Med 198, 1391-1402.

Toma, C., Pittenger, M.F., Cahill, K.S., Byrne, B.J., and Kessler, P.D. (2002). Human mesenchymal stem cells differentiate to a cardiomyocyte phenotype in the adult murine heart. Circulation 105, 93-98.

Trivedi, P.S., Tray, N.J., Nguyen, T.D., Nigam, N., and Gallicano, G.I. (2010). Mesenchymal Stem Cell Therapy for Treatment of Cardiovascular Disease: Helping people sooner or later. Stem Cells Dev 19, 1109-1120.

Xie, C.Q., Zhang, J., Xiao, Y., Zhang, L., Mou, Y., Liu, X., Akinbami, M., Cui, T., and Chen, Y.E. (2007). Transplantation of human undifferentiated embryonic stem cells into a myocardial infarction rat model. Stem Cells Dev 16, 25-29.

Xu, R., Chen, J., Cong, X., Hu, S., and Chen, X. (2008). Lovastatin protects mesenchymal stem cells against hypoxia- and serum deprivation-induced apoptosis by activation of PI3K/Akt and ERK1/ 2. J Cell Biochem 103, 256-269.

Yang, J., Liu, X., Bhalla, K., Kim, C.N., Ibrado, A.M., Cai, J., Peng, T.I., Jones, D.P., and Wang, X. (1997). Prevention of apoptosis by Bcl2: release of cytochrome $c$ from mitochondria blocked. Science 275, 1129-1132.

Zhang, J., and Cai, H. (2010). Netrin-1 prevents ischemia/reperfusion-induced myocardial infarction via a DCC/ERK1/2/eNOS (s1177)/NO/DCC feed-forward mechanism. J Mol Cell Cardiol 48, 1060-1070.

Zhang, M., Mal, N., Kiedrowski, M., Chacko, M., Askari, A.T., Popovic, Z.B., Koc, O.N., and Penn, M.S. (2007). SDF-1 expression by mesenchymal stem cells results in trophic support of cardiac myocytes after myocardial infarction. FASEB J 21, 3197-3207. 